\title{
Effect of Nitric Acid on Cutaneous and Plantar warts-a case report
}

\author{
Subramani Parasuraman \\ Unit of Pharmacology, AIMST University, Bedong 08100, Kedah, MALAYSIA.
}

\begin{abstract}
A 33-year-male with a history of plantar and cutaneous warts for six months was treated with topical salicylic acid preparation, without any improvement. He was accidentally exposed to nitric acid while working. He observed that nitric acid had a better healing index for his cutaneous warts. He then used nitric acid (10\%) to treat the plantar warts for two weeks. Nitric acid showed beneficial effects on cutaneous and plantar warts, but its clinical efficacy and mechanism of action in this context remains unknown. Nitric acid was used for the treatment of skin lesions since the last century. Recent clinical studies also showed mild acids such as citric and nitric acids
\end{abstract}

are beneficial against common warts.

Key words: Common warts, Human Papillomavirus, Nitric acid, Topical.

Correspondence :

Dr. Subramani Parasuraman

Unit of Pharmacology, AIMST University, Bedong 08100, Kedah, MALAYSIA.

E-mail: parasuraman@aimst.edu.my

DOI: 10.5530/jyp.2016.2.21

\section{INTRODUCTION}

A wart is generally a small, rough growth resembling a cauliflower or a solid blister, caused by viral infection specifically by any of the human papillomaviruses (HPV). ${ }^{1,2}$ Warts typically occur on humans' hands or feet, but also in other locations of the body. Some of the predominant warts are common warts (verruca vulgaris), flat warts, plantar warts, coalesced mosaic warts, filiform warts, periungual warts, anogenital warts, oral warts and respiratory papillomas. ${ }^{2,3}$ The most common warts are caused by HPV types 2 and, 4 . Plantar warts (myrmecia) are caused by HPV type 1 and also by types 2, 3, 4, 27, 28 and, 58..$^{3-5}$ This can be managed by destructive methods (surgery, laser and electrodesiccation), caustic acid (mono-, di- or tri-chloracetic acid), chemotherapeutic agents (podophyllotoxin, bleomycin), hypersensitivity agents (dinitrochlorbenzene/DNCB, diphenylcyprone, immune response modifiers, imiquimod cream) and miscellaneous agents (salicylic acid preparations, tretinoin, cimetidine). ${ }^{6}$ The present case report describes the effect of nitric acid on plantar and cutaneous warts. Patient informed consent was obtained for publishing this case report.

\section{CASE DESCRIPTION}

A 33-year-male suffered with plantar and cutaneous warts for six months. The plantar warts prevented him from walking on flat surfaces and inflicted severe pain on the site of wart growth. This was examined by a dermatologist and treated with topical salicylic acid preparation. Salicylic acid was applied on the infected area for four weeks. However, no changes were observed in the infected area and the patient discontinued the follow-up. One day he accidentally spilt nitric acid (2N) on the cutaneous warts in the middle finger of right hand. Immediately it caused a mild irritation on the warty area and caused deceleration (skin color to mild yellow color). He also observed some improvement on the infected area. After two weeks, the wart infected tissue peeled out naturally and new tissue grew. The infection totally healed.
Later, he prepared $10 \%$ nitric acid solution and applied it once daily on plantar warts present in the right leg for two weeks. Two days after initial application of nitric acid, mild to moderate burning sensation was felt in the infected area. After two weeks of application, the warts peeled out automatically and new tissue grew in the infected area. This event/ incident gave an inkling that nitric acid could be beneficial against plantar and cutaneous warts.

\section{DISCUSSION}

In the present case, nitric acid showed significant effect on both the plantar and cutaneous warts. In the nineteenth and early twentieth centuries, fuming nitric acid (topical) was used for the treatment of animal bites. ${ }^{7}$ Dilute nitric acid solution used for the treatment of skin lesions. In animals, diluted nitric acid (33.4\%) produced erythematous reaction in 15 to 45 min. ${ }^{8}$ Vali and Ferdowsi, reviewed and reported that non-pharmacological techniques such as chemical destruction with acids (acetic acid, lactic acid, nitric acid, salicylic acid or trichloroacetic acid) are frequently used for the treatment of warts. ${ }^{9}$ Nitric acid is a caustic and causes the destruction of tissue; therefore, they are used in treatment of hyperkeratosis or hyperplastic tissue. Caustics are also used for the destruction of tumours such as basaliomas and xanthelasmas. ${ }^{10}$ Heaton et al., studied the clinical effect of nitric acid in patients and revealed the nitric acid effect (destruction of small lesions by tissue denaturation) in their study. ${ }^{11}$ Verrutop $^{\odot}$ is a topical preparation used for the treatment of warts which is formulated by using $65 \%$ nitric acid combined with organic acids, causing a redox reaction. The active substance present in this preparation is nitrogen dioxide, which acts by denaturing proteins. ${ }^{12}$ Further clinical studies or clinical trials are required to understand the clinical efficacy of $10 \%$ nitric acid against plantar and cutaneous warts. 


\section{REFERENCES}

1. de Koning MN, Quint KD, Bruggink SC, Gussekloo J, Bouwes Bavinck JN, Feltkamp MC, et al. High prevalence of cutaneous warts in elementary school children and the ubiquitous presence of wart-associated human papillomavirus on clinically normal skin. Br J Dermatol. 2015;172:196-201.

2. Riordan-Eva (Ed). Vaughan \& Asbury's general ophthalmology. $17^{\text {th }}$ ed, New York: McGraw Hill Lange Publishers. 2007. [Source: Google Books; Last accessed on 23/01/2016]

3. Lipke MM. An armamentarium of wart treatments. Clin Med Res. 2006;4(4):27393.

4. Treatment of Warts: Cryotherapy and Salicylic Acid. Available in http://flipper.diff. org/app/items/5521 [Last accessed on 23/01/2016]

5. Leto Md, Santos Júnior GF, Porro AM, Tomimori J. Human papillomavirus infection: etiopathogenesis, molecular biology and clinical manifestations. An Bras Dermatol. 2011;86:306-17.

6. Klostranec JM, Kolin DL, editors. Toronto Notes: A comprehensive medical reference \& review for MCCOE I \& USMLE II. $28^{\text {th }}$ ed. Toronto, ON: Type \& Graphics Inc; 2012. p-D29.
7. Modell W. Drugs in Current Use. New York, Springer Publishing Company, Inc. 1958.

8. Use of dilute nitric acid solutions for treating certain skin lesions, (US patent No.: US $4595591 \mathrm{~A} ; 1986)$

9. Vali A, Ferdowsi F. Evaluation of the efficacy of $50 \%$ citric acid solution in plane wart treatment. Indian J Dermatol 2007;52:96-8.

10. Monti M, Motta S. Chapter 152. Topical preparations and vehicles. In Katsambas A, Lotti T, Dessinioti C, D'Erme AM, editors. European handbook of dermatological treatment. $3^{\text {rd }}$ ed. New York: Springer; 2015.

11. Heaton $\mathrm{CL}$, Lichti HF, Weiner M. The revival of nitric acid for the treatment of anogenital warts. Clin Pharmacol Ther. 1993;54:107-11.

12. A new treatment for warts (patented); US Registry for trade mark 79110315 Available in http://www.auriga-int.com/sites/default/files/public/verrutop_dermatologie pratique_a_new treatment_for_warts_2009.pdf [Last accessed on 28/01/2016] 